\title{
A demografia brasileira e o declínio da fecundidade no Brasil: contribuições, equívocos e silêncios*
}

\author{
José Alberto Magno de Carvalho** \\ Fausto Brito*
}

\begin{abstract}
A população brasileira vivenciou, no final do século passado, rapidíssimo declínio da fecundidade. Sua taxa de fecundidade, em três décadas, passou de 5,8 para apenas 2,3! O artigo analisa as atitudes e posições dos estudiosos da população diante de tal fenômeno. Para entendê-las, há de se levar em conta o contexto internacional polarizado pelos blocos socialista e capitalista. Entre os cientistas sociais brasileiros predominava, em oposição aos neomalthusianos e à política americana, posição clara contra a presença do Estado no campo da reprodução. Tinham duas fortes convicções: 1) não havia, em geral, demanda por anticoncepção e 2) o ritmo do crescimento populacional e seu tamanho eram neutros, do ponto de vista do bem-estar social. O grande embate ideológico está ultrapassado. A transição da fecundidade no Brasil já avançou muito. No entanto, há segmentos de mulheres, as mais pobres, que ainda carecem de informação e de acesso aos meios para regular sua prole. Por outro lado, a sociedade não está tirando partido de algumas oportunidades geradas pelo declínio da fecundidade, nem se preparando para enfrentar os novos desafios, que são conseqüência desse mesmo declínio. Ainda predominam silêncios, entre demógrafos e estudiosos da população, sobre esses aspectos.
\end{abstract}

Palavras-chave: Transição da fecundidade. Controle da natalidade. Neomalthusianismo. Planejamento familiar.

Falar da diminuição da fecundidade no Brasil é também entrar em assunto controverso em que os diversos contendores desqualificam, de saída, os argumentos que contrariam suas posições.

São visões radicais e incompatíveis.

No debate sobre planejamento familiar é preciso medir as palavras. Cada expressão usada será o signo de um complexo ideológico que tem as suas raízes na maneira de ver a conservação ou a mudança na estrutura econômica. Estas posições, quando cristalizadas, servem de freio à análise e dificultam a leitura dos fatos.

Ao ser retomada agora a discussão, depois de um longo esquecimento, parece que surgiram as condições para a elaboração de uma posição não comprometida com as já históricas contendas entre natalistas e antinatalistas. Não foi só o tempo que desgastou o debate, foram também as mudanças ocorridas na sociedade e a presença de novos atores em nossa arena política.

(Ruth Cardoso, 1983, p. 2)

\footnotetext{
" Os autores receberam críticas e sugestões dos colegas André Junqueira Caetano, Charles Wood, Clotilde Paiva, Diana Sawyer, Duval Fernandes, George Martine, Ignez Helena Perpétuo, Irineu Rigotti, Laura Wong, Mariza Magalhães e Paulo Paiva, aos quais agradecem. Obviamente, nem todas foram incorporadas ao trabalho, cuja responsabilidade cabe unicamente aos autores. ${ }^{*}$ Professor do Departamento de Demografia e pesquisador do Centro de Desenvolvimento e Planejamento Regional (Cedeplar) da Faculdade de Ciências Econômicas (FACE) da Universidade Federal de Minas Gerais (UFMG).
} 
Essas citações da professora Ruth Cardoso, escritas há mais de duas décadas, fornecem elementos importantes para uma reflexão crítica sobre o papel desempenhado pela comunidade demográfica brasileira no processo de rápido declínio da fecundidade no país. Apesar do demasiado otimismo na última citação, pois alguns ecos das contendas até hoje obscurecem corações e mentes, elas servem como uma ótima introdução a este trabalho, cujo objetivo é analisar as contribuições, os equívocos e, em particular, os silêncios dos demógrafos e estudiosos da população sobre o rápido declínio da fecundidade no Brasil e suas conseqüências.

A população feminina mais pobre tem sido vítima da desinformação sobre as possibilidades de regulação da sua fecundidade e, mais ainda, da dificuldade de acesso aos quase sempre deficientes serviços públicos de saúde. A conseqüência social tem sido dramática, contribuindo, decisivamente, para privar parte das mulheres de sua cidadania plena. Tal como quando se vivia sob o manto de um debate ideológico, hoje totalmente esclerosado, os demógrafos e estudiosos da população, em sua maioria, ainda se mantêm silenciosos quanto ao atendimento, mediante políticas públicas, às necessidades dessa parcela da população feminina.

O silêncio também prevalece, de modo geral, quanto às conseqüências do novo padrão demográfico brasileiro, no que diz respeito às oportunidades criadas e aos novos desafios. Tanto aquelas quanto estes exigem uma nova postura da sociedade e do Estado, e nesse processo a demografia tem uma responsabilidade social única e insubstituível.

Este artigo não deseja reviver uma estridência inócua. $\mathrm{O}$ tom pretende-se analítico. Para tanto, será feita uma revisão histórica da dimensão política que a questão do crescimento populacional assumiu na segunda metade do século $X X$.

\section{A questão do crescimento populacional - a agenda política internacional}

O rápido crescimento populacional tornou-se fundamental na agenda política internacional após a Segunda Grande Guerra. Os países mais desenvolvidos, em sua maioria, já tinham avançado na transição em direção a um desacelerado ritmo de crescimento populacional. Entretanto, os países então chamados de subdesenvolvidos, onde se localizava a maior parte da população mundial, vivenciavam o declínio das taxas de mortalidade, combinado com altas taxas de fecundidade. Nos anos 50, esses países, entre eles o Brasil, apresentavam taxas de crescimento populacional muito acima daquelas observadas entre os países mais desenvolvidos em toda a sua história pósrevolução industrial.

A questão do crescimento populacional dentro da agenda internacional apresentava duas dimensões fundamentais. A primeira referia-se às possibilidades do crescimento da economia com uma oferta ilimitada de mão-de-obra, em um contexto de intensa urbanização. A segunda, aos problemas políticos decorrentes da pressão demográfica sobre a terra em regiões estagnadas, como o semi-árido nordestino brasileiro.

A primeira dimensão, a princípio, era analisada com um certo otimismo, tendo como base as teorias sociológicas sobre a modernização da sociedade e as teorias econômicas sobre o desenvolvimento da economia (Lewis, 1963; Germani, 1969). Ambas as perspectivas apostavam que as migrações internas transfeririam, gradualmente, a população das áreas rurais mais atrasadas e com produtividade do trabalho próxima de zero para as áreas urbanas, onde a sociedade moderna articulava-se a uma economia que, sustentada pelo crescimento industrial, apresentava alta produtividade, alimentada por um acelerado progresso técnico. Esperava-se que as populações nessas novas sociedades urbanas e industriais, à semelhança do que já havia acontecido nos países mais desenvolvidos, 
experimentariam um generalizado declínio nos níveis de fecundidade e, conseqüentemente, uma redução do crescimento demográfico.

Em síntese, o desenvolvimento da economia e a modernização da sociedade seriam os fatores mais importantes para reduzir o crescimento populacional. Portanto, não haveria necessidade de retomar as teses de economistas como Thomas Malthus, do final do século XVIII e início do século XIX, que insistiam nos desequilíbrios entre o crescimento demográfico e 0 crescimento da economia (Malthus, 1951).

Entretanto, os países mais ricos, os Estados Unidos em particular, e as organizações multilaterais, como a Organização das Nações Unidas e o Banco Mundial, logo se convenceram de que o otimismo demográfico, baseado no binômio desenvolvimento-modernização, estaria sendo atropelado, nos países subdesenvolvidos, pelas crescentes taxas de crescimento vegetativo (declínio da mortalidade e fecundidade alta e estável) e pela migração rural-urbana. No Brasil, o rápido crescimento populacional, somado à estagnação em grande parte das áreas rurais, nos anos 60 , e à modernização agrícola patrocinada pelas políticas públicas, nos anos 70 , tinha proporcionado uma transferência maciça de população para as cidades, ${ }^{1}$ principalmente para os maiores centros urbanos, acelerando o processo de urbanização a taxas historicamente inéditas.

Contudo, o bom desempenho da economia brasileira, inclusive no que se refere à geração de empregos - principalmente a partir do Plano de Metas do governo JK (1955-1960) e mais acentuadamente nos anos 70 -, não tinha sido suficiente para integrar a grande maioria da população à sociedade moderna, tendo, ademais, ampliado os desequilíbrios regionais.
A segunda dimensão da questão demográfica dentro da agenda política internacional tinha a ver com as relações estabelecidas entre o crescimento demográfico e o comportamento político das populações mais pobres. Nesse caso, o Nordeste brasileiro era exemplar, principalmente depois da organização das Ligas Camponesas no final dos anos 50 e início da década de 60, contemporâneas da Revolução Socialista em Cuba. A enorme crise social no Nordeste, decorrente de uma miséria secular, era vista como tendo grande potencial revolucionário, ampliado por sua volumosa população, que crescia a taxas muito elevadas. Levava-se em conta, ainda, que o desenvolvimento da economia brasileira não se mostrava capaz de retirar o Nordeste da sua histórica estagnação.

A importância da questão demográfica no Nordeste brasileiro era também destacada pelo grande economista Celso Furtado. Dentre os projetos a serem implementados pela Superintendência de Desenvolvimento do Nordeste (Sudene), criada em 1959, da qual Furtado foi o seu principal idealizador e primeiro dirigente, incluía-se uma grande transferência de população da região do semi-árido nordestino para o Maranhão, onde uma reforma agrária deveria contribuir para absorvê-la produtivamente. Como justificativa de tal projeto, afirmava-se que a densidade demográfica do semi-árido nordestino era incompatível com a organização de uma economia produtiva, em particular devido à sua estrutura fundiária, o que potencializava a crise social que acompanhava as grandes secas (Furtado, 1959). Deve-se observar que a inércia política da população do semi-árido, a partir da segunda metade da década de 50 , foi sendo substituída pela mobilização dos camponeses, organizados em ligas e sindicatos.

\footnotetext{
${ }^{1}$ Na década de 60, as migrações entre campo e cidade no Brasil representaram uma perda líquida, para a população rural, de 13,6 milhões de pessoas (aí incluídos os efeitos indiretos de migração), que correspondia a 25\% do que seria a população rural em 1970 , caso tivesse permanecido fechada durante a década. Nos anos 70 , esses valores foram de 18,2 milhões e $32 \%$, respectivamente. Devido a esses fluxos, a população urbana foi, em 1970, 35\% e, em 1980, 29\% maior do que seria na ausência, em cada década, de fluxos migratórios entre os setores rural e urbano (Carvalho e Garcia, 2002).
} 
O otimismo demográfico decorrente do binômio desenvolvimento-modernização, atropelado pela própria realidade do mundo subdesenvolvido, que, aparentemente, não repetia a secular transição demográfica dos países desenvolvidos, sofreu, ainda, um impacto maior e decisivo: o da Guerra Fria. A tensão internacional, após a Segunda Guerra Mundial, entre os países dos blocos capitalista e socialista estabeleceu nítidas fronteiras territoriais e ideológicas, dentro das quais os países hegemônicos estabeleciam as suas estratégias de confronto e negociação. A Revolução Chinesa em 1949 e a decorrente crise da Coréia, na primeira metade dos anos 50 , e, principalmente, a Revolução Cubana em 1959 mostraram a instabilidade da divisão política internacional e levaram os Estados Unidos a uma agressiva política de colaboração econômica, política e militar com os países latino-americanos, inclusive o Brasil.

O confronto político-ideológico internacional acabou transformando, definitivamente, no mundo capitalista, o otimismo demográfico em um pessimismo de cunho malthusiano. Acreditava-se, então, que a redução do rápido crescimento demográfico de países como o Brasil não ocorreria sem uma eficiente política de controle da natalidade. Mais ainda, dentro da agenda internacional, o crescimento populacional tornou-se uma variável politicamente estratégica e o controle da natalidade passou a fazer parte de pacotes de colaboração econômica, política e militar.

As pressões norte-americanas ${ }^{2}$ e dos organismos multilaterais para que fossem implementadas políticas de controle da natalidade estendiam-se a todos os países em desenvolvimento, em particular à América Latina e Ásia. A Índia, então um país extremamente pobre e com a segunda maior população do mundo, foi um laboratório de pesquisas acadêmicas e de políticas oficiais de controle de natalidade, cujos resultados, em termos de declínio da fecundidade, foram praticamente inexpressivos. O México foi um outro exemplo de esforço governamental na implementação de políticas populacionais, através do Conselho Nacional de População (Conapo), criado em $1974 .^{3}$

O interessante é que o único país da América Latina que de fato implementou políticas nesta área, com êxito indiscutível, foi Cuba, obviamente sem nenhuma pressão norte-americana. A taxa de fecundidade total (TFT) de Cuba, que nos anos 50 apresentava níveis relativamente baixos, em torno de 3,6 filhos nascidos vivos por mulher, experimentou significativo aumento logo após a Revolução, passando para 4,5 e 4,3 nos qüinqüênios 1960-1964 e 19651969, respectivamente (Alfonso Fraga, 2005). Comandada pelo Estado, houve uma ampla mobilização popular, utilizando, inclusive, o sistema educacional, com o objetivo de implementar políticas de planejamento familiar, associadas a políticas de saúde materno-infantil. Há um número especial da Revista Brasileira de Estudos de População (vol. 4, n. 1, jan.-jul. 1987) com instigantes artigos sobre as experiências cubanas, mexicana e chinesa, entre outras. Cuba, na verdade, seguiu a tradição dos países socialistas, iniciada na antiga

\footnotetext{
${ }^{2}$ A posição oficial dos Estados Unidos foi, durante décadas, favorável à implementação de políticas de controle de natalidade nos países subdesenvolvidos, como instrumento imprescindível à superação do "círculo vicioso da pobreza". Aquele país liderou a corrente controlista nos diversos fóruns e Conferências Internacionais de População, inclusive na de Bucareste, em 1974. Em 1984, na Conferência do México, durante o governo Reagan, teve, surpreendendo seus aliados europeus, uma posição mais moderada, chegando, inclusive, a explicitar em sua declaração oficial que "o crescimento populacional, em si mesmo, é um fenômeno neutro" (citado por Finkle e Crane, 1985, p. 2), assim como a afirmar que os fundos governamentais americanos não deveriam ser usados em atividades relacionadas ao aborto ou em apoio a instituições que o promovessem (Finkle e Crane, 1985; Demeny, 1985). Nos governos seguintes, os Estados Unidos voltaram a apoiar, no exterior, em maior ou menor grau, as atividades em planejamento familiar, com exceção do atual (George W. Bush), que tem uma posição semelhante à do governo Reagan. 3 Índia e México foram os dois países analisados por Coale e Hoover no livro Population growth and economic development in lowincome countries, de 1958, que proveu aos neomalthusianos os argumentos mais convincentes no campo da economia, apesar de os autores defenderem uma posição intermediária entre as correntes intervencionista e não-intervencionista quanto ao crescimento populacional (Coale, 1978, p. 415-416).
} 
União Soviética. Logo após a Revolução Bolchevique, em 1917, foi elaborado um conjunto de leis sobre aborto, esterilização e casamento, ligadas a uma nova concepção do papel da mulher dentro do socialismo e à necessidade de sua mobilização como mão-de-obra. De fato, a antiga União Soviética não enfrentava rápido crescimento populacional, mas tinha problemas relacionados à distribuição espacial de sua população. Com o objetivo de redistribuí-la, desenvolveu-se, no período stalinista, um projeto de reforma agrária, acompanhado de uma política de migração forçada, que se transformou numa tragédia de dimensões humanas incomensuráveis (Carr, 1972).

A China, também um país fora da esfera de influência norte-americana desde a Revolução Comunista de 1949, certamente foi onde se levou, após um comportamento oscilante e, às vezes, ambivalente, às últimas conseqüências a política de controle da natalidade. Nos anos 70, o controle da natalidade foi considerado, definitivamente, uma questão de Estado. Além das medidas anticonceptivas, introduziu-se o "controle malthusiano do casamento": na cidade, para se casar, os homens deveriam ter, no mínimo, 28 anos de idade e as mulheres, 25 anos; no campo, deveriam ter 25 e 23 anos, respectivamente. O ápice do controle da natalidade foi a política de "um casal, um filho", que ainda prevalece e cujas conseqüências sociais e demográficas têm sido observadas com pessimismo (Population Reports, 1982; Winckler, 2002; Greenhalgh, 2003).

\section{A questão do crescimento populacional - a agenda política nacional}

O golpe militar de 1964 no Brasil contou com a decisiva colaboração dos Estados Unidos, interessados em manter o país dentro das fronteiras do capitalismo. $O$ regime político emergente, gradualmente, mas de um modo cada vez mais radical, implantou um governo autoritário que cerceava, sem limites, as liberdades fundamentais do povo brasileiro. A legislação sobre a segurança nacional e os atos institucionais, em particular o de $n^{\circ} 5$, de 1968, e uma repressão que não obedecia aos parâmetros formais foram instrumentos que consolidaram a ditadura militar no Brasil.

Do ponto de vista demográfico, contudo, a forte influência dos Estados Unidos no Brasil não se traduziu em políticas públicas de controle da natalidade, apesar da ostensiva pressão direta, através da United States Agency for International Development (Usaid), ou indireta, por meio de algumas fundações privadas e de organismos internacionais, como o Banco Mundial e as Nações Unidas, onde a posição americana era hegemônica.

As posições referentes ao controle de natalidade se diferenciavam dentro dos grupos que davam sustentação interna ao regime militar brasileiro. Os militares, que assumiram a responsabilidade direta pelo controle do aparelho estatal, defendiam, em sua maioria, a tese de que o território brasileiro comportaria uma população maior e, portanto, não se atemorizavam com o problema do rápido crescimento demográfico. Ao contrário, consoante com a perspectiva predominante na época, de defesa da segurança nacional, crescer e redistribuir a população, de modo a ocupar o amplo espaço vazio nacional, era um objetivo estratégico para os militares. Um bom exemplo foi o ambicioso e malsucedido projeto de colonização da região amazônica, que tinha como meta transferir cerca de 1,5 milhão de famílias da região onde existiam muita população e pouca terra, o Nordeste, para a Amazônia, onde existiam muita terra e pouca população (Martine, 1987).

Por outro lado, uma proporção significativa dos tecnocratas, associados aos militares na administração pública, mostrava-se defensora da necessidade de políticas públicas que contribuíssem, efetivamente, para o controle da natalidade. A justificativa era a de que o crescimento da economia e, principalmente, a redução da pobreza seriam por demais facilitados se o ritmo do crescimento da população fosse menor. Um dos expoentes dessa corrente foi o economista Mário Henrique 
Simonsen, ministro, por duas vezes, dos governos militares, que seguia a tradição analítica de Roberto Campos, para quem "a tecnologia agrícola matou o demônio malthusiano na primeira metade do século XX. A tecnologia bioquímica o ressuscitou na segunda metade do século" (citado por Simonsen, 1975).

Simonsen faz uma crítica ao que ele denomina a aritmética dos coelhos, ou seja, à tradição católica brasileira, que teria levado a população a seguir à risca o preceito bíblico "crescei e multiplicai-vos", num ufanismo demográfico que se esquecia que a população é o "denominador da fórmula da renda per capita", cujo rápido crescimento contribuía negativamente para o bem-estar das pessoas. Para ele, a assertiva dos ufanistas de que a solução seria "aumentar o banquete e não diminuir o número de comensais" era equivocada, porque não se tratava de "reduzir o número de comensais, mas, apenas, de refrear a sua taxa de crescimento". Em segundo lugar, para Simonsen, o

argumento de que o importante seria acelerar a taxa de crescimento do produto real e, não, conter o aumento da população revelava a incapacidade de raciocinar com funções de duas variáveis.

De fato, ambas as preocupações eram relevantes, não havendo razão para que uma excluísse a outra. "Dentro das boas regras da aritmética, se fosse possível aumentar o dividendo e conter o divisor, tanto melhor para o quociente". E, mais importante do que tudo isso, afirmava

que se escapamos do círculo vicioso da pobreza absoluta, talvez continuemos enredados no da pobreza relativa [...] se não conseguirmos deter a nossa explosão populacional. (Simonsen, 1975, p. 99 e 115)

Do ponto de vista da política populacional, Simonsen defendia a necessidade de superar o fatalismo demográfico, segundo o qual

a taxa de natalidade acabará declinando com a urbanização e o aumento da renda real per capita [...] e dificilmente será possível antecipar tal declínio por simples medidas de política demográfica. (Simonsen, 1975, p. 115)
Para ele, "não se tratava de criar o Estado-Herodes, mas compreender que o planejamento familiar afastaria o risco da paternidade irresponsável, inserindo-o dentro de uma política educacional" (Simonsen, 1975, p. 99 e 115).

A posição desse segmento da tecnocracia não foi suficientemente influente para incluir a questão do crescimento demográfico na agenda governamental, até porque outros grupos importantes no cenário político, como a Igreja Católica, eram francamente contrários a qualquer política de regulação da fecundidade e até de oferta de serviços neste campo. Acrescente-se que o Estado no Brasil, aí incluídas as elites que sempre o governaram em seus diferentes momentos históricos, nem sempre considerou a população uma questão neutra no desenvolvimento do país e na construção da nação. Ao contrário, recorrentemente preocupou-se com a questão populacional, principalmente com a formulação de políticas migratórias, no que se refere tanto ao estímulo da imigração internacional quanto à redistribuição interna da população, mediante projetos de expansão da fronteira agrícola e políticas de ordenamento territorial.

Não se deve esquecer que as políticas de imigração internacional no final de século XIX e princípio do século XX tinham como objetivo buscar no mercado internacional não somente a mão-de-obra necessária à economia, mas também o aperfeiçoamento étnico do povo brasileiro, que as elites desejavam fosse mais branco e industrioso, como os europeus (Brito, 2004, p. 17).

A diversidade de opiniões dentro dos governos militares levou-os a uma deliberada omissão, que se, por um lado, não os conduziu à formulação explícita de uma política de controle da natalidade, por outro, possibilitou o livre trânsito no governo dos tecnocratas favoráveis ao controle da natalidade e o livre acesso à população de organizações privadas nacionais e internacionais de inspiração neomalthusiana, que agiam principalmente no Nordeste do país.

A politização da questão do crescimento demográfico pelos Estados Unidos, 
no contexto do pessimismo malthusiano, e - lugar estratégico reservado à sua desaceleração dentro da sua política internacional levaram, principalmente na América Latina, a um confronto políticoideológico e científico entre aqueles que defendiam as políticas de controle da natalidade e a quase unanimidade dos cientistas sociais, constituídos, majoritariamente, por professores e pesquisadores com fortes convicções nacionalistas e socialistas, entre eles a grande maioria dos demógrafos. Acrescente-se que, no Brasil, a forte resistência à política intervencionista norte-americana e à sua sustentação ao regime ditatorial levou a maioria dos cientistas sociais interessados ou dedicados aos estudos populacionais, convictos opositores do regime militar, a uma postura ainda mais radical contra toda política que pudesse ser relacionada, direta ou indiretamente, com o planejamento familiar, qualquer que fosse seu matiz.

Ademais, estavam convencidos de que não havia demanda insatisfeita por anticoncepção. Por lógico, se o Estado porventura se fizesse presente nesta área, qualquer declínio da fecundidade, em conseqüência de sua ação, seria um fruto inaceitável da coerção. Apesar de o governo brasileiro implementar, explicitamente, desde os anos 50 até o final da década de 70 , políticas de redistribuição de população, mormente pela expansão da fronteira agrícola, a atenção da grande maioria dos demógrafos estava concentrada na oposição aos chamados neomalthusianos, isto é, àqueles que defendiam a implementação de políticas de população - no caso, estrito senso, políticas de controle da natalidade. Opunham-se, no Brasil, a qualquer presença do Estado no domínio exclusivo das decisões dos indivíduos e casais sobre o número adequado de filhos.

A politização excessiva da questão do crescimento demográfico levou os chamados neomalthusianos a superestimar a eficiência de políticas de controle da natalidade sobre os níveis de fecundidade, assim como os efeitos positivos da desaceleração do aumento populacional sobre o crescimento da economia e o equilíbrio social e político. Também impeliu seus opositores a subestimarem a demanda genuína por anticoncepção e os efeitos negativos para os indivíduos e as famílias, assim como para a sociedade e para a economia, advindos de uma fecundidade permanentemente alta e do conseqüente rápido crescimento populacional.

Dos dois lados da contenda sobre o controle da natalidade havia apenas um ponto consensual, nunca reconhecido como tal: não se deveria esperar por um declínio natural da fecundidade nos países então chamados de subdesenvolvidos, obviamente aí incluído o Brasil, no curto e médio prazos. A corrente neomalthusiana, com a sua visão pessimista - e muitas vezes catastrófica - do rápido crescimento demográfico, propugnava por políticas que interferissem diretamente no nível da fecundidade, conduzindo as famílias pobres a superarem a sua "irracionalidade" econômica e social no tocante ao número de filhos. Seus antagonistas, inclusive a maioria dos demógrafos brasileiros, estavam convictos de que só o verdadeiro desenvolvimento econômico, com mudanças estruturais profundas, levaria os casais a planejar sua prole. Como a economia brasileira crescia a taxas positivas muito altas, afirmava-se, então, que estava havendo crescimento econômico, não, porém, desenvolvimento econômico. Só neste último caso a fecundidade declinaria de modo natural, o que, por si só, não corresponderia a um ganho para indivíduos e para a sociedade, uma vez que o número de filhos e o ritmo de crescimento populacional seriam neutros, do ponto de vista do bemestar social.

A compreensão teórica da neutralidade da população em face do crescimento da economia e do bem-estar social buscava a sua fundamentação, em muitos casos, nas críticas feitas por Marx a Malthus. Segundo o primeiro, o grave equívoco do segundo foi acreditar que o excedente demográfico nos países capitalistas era decorrente do crescimento demográfico.

O economista alemão não colocava em dúvida a existência de um excedente demográfico; ao contrário, considerava que 
ele fazia parte da própria natureza da acumulação capitalista, que produz, constantemente, devido ao progresso técnico, uma população supérflua. O crescimento da população trabalhadora seria sempre mais rápido do que o do capital variável, gerando, conseqüentemente, um número de desempregados - o exército industrial de reserva - estruturalmente determinado pelo processo de acumulação. Para Marx, a contração ou expansão do exército industrial de reserva seria uma função não do tamanho absoluto da população, mas das proporções dos exércitos economicamente ativo e da reserva em que se divide a classe trabalhadora, segundo os diferentes ciclos industriais (Marx, 1975).

Esta conclusão poderia levar a uma leitura de que o tamanho da população e, logicamente, o seu crescimento seriam neutros em relação à dimensão do excedente populacional. Porém, se considerarmos a própria tese de que a velocidade do crescimento da população trabalhadora seria sempre maior do que a do capital variável, o seu tamanho e crescimento seriam determinantes na divisão entre as proporções da população economicamente ativa e da reserva. Pois, quanto maior o crescimento e, portanto, o tamanho da população, maior o excedente populacional. Nesta perspectiva, a população, ainda que por motivos diferentes dos enunciados por Malthus, não poderia ser considerada uma variável neutra.

Os debates teóricos e as discussões políticas sobre a neutralidade da questão demográfica, isto é, sobre as implicações do tamanho e ritmo de crescimento da população, e sobre a necessidade ou não das políticas de regulação da fecundidade estenderam-se da segunda metade da década de 60 até os anos 80 . Entretanto, segundo alguns estudiosos da população, o significado real do planejamento familiar para os indivíduos e famílias de baixa renda - que carregavam o ônus da responsabilidade pelas rápidas taxas de reprodução não foi objeto de discussão explícita na época, em vista da reação extremamente negativa às pressões internacionais e da predominância de atitudes de laissez-faire com respeito ao assunto. (Martine e Faria, 1986$, p. 7$)$

\section{O rápido declínio da fecundidade no Brasil: e agora?}

Enquanto a contenda se desenvolvia, a história passava ao largo, alheia àquele radicalismo inócuo e à existência ou não de políticas de controle da natalidade ou de planejamento familiar. Já havia indicadores de que a fecundidade das mulheres brasileiras começara a declinar. $O$ viés ideológico e a certeza sobre a implausibilidade de sua queda, produto do debate e do contexto no qual se realizava, impediram alguns demógrafos, como Carvalho (1973), de enxergar essa realidade. A sua tese de doutorado tinha elementos que indicavam, claramente, um persistente declínio da fecundidade em regiões responsáveis por $61 \%$ da população brasileira em 1970.

As séries $P / F,{ }^{4}$ resultantes da aplicação da técnica de fecundidade de Brass aos dados do Censo de 1970, que deveriam ser rapidamente decrescentes em contextos de fecundidade constante, apresentaram-se constantes, até crescentes, no Sul e Sudeste brasileiros, ao contrário daquelas das demais regiões. $O$ Anexo apresenta as séries $P / F$ das populações que cobrem todo o Sul e Sudeste, assim como aquelas do Norte,$^{5}$ Nordeste Central ${ }^{6}$ e do país como um todo. ${ }^{7}$ Estavam a indicar, indubitavelmente, no Sul e Sudeste, persistente e significativo

\footnotetext{
${ }^{4} P$, parturição, refere-se ao número médio de nascidos vivos, por mulher, até uma determinada idade. $F$ corresponde à fecundidade corrente acumulada até a mesma idade. A fecundidade corrente é obtida a partir da informação, por idade da mulher, do número de filhos nascidos vivos nos 12 meses anteriores à data do censo ou survey.

${ }^{5}$ Acre, Amazonas, Pará, Rondônia, Roraima e Amapá.

${ }^{6}$ Ceará, Rio Grande do Norte, Paraíba, Pernambuco e Alagoas.

${ }^{7}$ Ao se analisar o comportamento da série $P / F$ deve-se desconsiderar, por razões teóricas e também relacionadas à qualidade dos dados, o primeiro valor, isto é, aquele das mulheres com 15 a 19 anos de idade.
} 
declínio da fecundidade, enquanto nenhuma conclusão, sequer inferência, poder-seia tirar no tocante às outras regiões. Da série do país como um todo, se analisada cuidadosamente, poder-se-ia levantar uma hipótese robusta, qual seja, de que já estaria havendo, pelo menos durante os anos 60 , queda sistemática dos níveis de fecundidade.

Poder-se-ia esperar que Carvalho (1973), diante de tais evidências, inferisse ou pelo menos levantasse a hipótese de que o país já teria entrado no processo de transição de uma fecundidade alta a uma fecundidade baixa, visto que a fecundidade vinha caindo nas regiões brasileiras mais desenvolvidas de forma continuada. Já se sabia, então, que nos países onde o processo de transição se encontrava avançado, o declínio da fecundidade começara nos grupos e regiões mais desenvolvidas para, em seguida, espalhar-se por toda a população.

A mesma falta de acuidade repete-se em trabalho imediatamente posterior. Ainda baseado em sua tese de doutorado, analisando a situação demográfica do Nordeste, Carvalho (1975, p. 29 e 35) afirma:

Seus níveis de fecundidade são elevadíssimos [...] Historicamente, tem sido mais fácil baixar os níveis de mortalidade, uma vez que a queda da fecundidade depende, antes de tudo, de um verdadeiro desenvolvimento socioeconômico. [...] No que tange ao Brasil como um todo, observa-se uma alta contínua no seu potencial de crescimento [...] Parece-nos que a crença [...] de que o Brasil já começou a experimentar uma queda duradoura em suas taxas de crescimento não se apóia em uma boa base científica.

Apesar de o Censo de 1970 já trazer indicadores do declínio da fecundidade no Brasil, estes não foram devidamente detectados pelos demógrafos e estudiosos da população, submersos no confronto político-ideológico. Os dados das PNADs de 1972 e 1976 confirmaram, claramente, o declínio da fecundidade no Brasil nos anos
70. A TFT tinha se reduzido em $5 \%$, entre 1970 e 1972, e 22\% entre 1972 e 1976 (Carvalho, 1980, p. 537).

Foi um "Deus nos acuda" nos dois pólos da contenda, pois a realidade estava desmentindo a única tese sobre a qual concordavam: não havia no país demanda generalizada pela redução do número de filhos e, conseqüentemente, pela anticoncepção. Foram anos de perplexidade na comunidade demográfica brasileira, incapaz de prever, ainda que como uma probabilidade, o fenômeno, muito menos sua magnitude. ${ }^{8}$

Chegou-se mesmo a argumentar, ignorando-se o já prenunciado pelos dados do Censo de 1970, que o declínio aparente da fecundidade poderia ser conseqüência de erros de amostragem da PNAD de 1972. Porém, os dados da mesma pesquisa do IBGE, em 1976, atropelaram tal argumento, reiterando uma queda rápida e significativa da fecundidade na maioria das regiões do país.

Restava, pois, explicar o que para a grande maioria dos demógrafos e estudiosos de população apresentava-se como absolutamente inusitado. Algumas análises levaram em conta os chamados fatores inibidores da fecundidade, utilizando-se dos determinantes próximos de Bongaarts. Destaca-se, no caso, o trabalho de Elza Berquó, apresentado em 1980 em um seminário do Grupo de Trabalho sobre o Processo de Reprodução da População, do Conselho Latino-Americano de Ciências Sociais (Clacso), em Teresópolis (RJ), que arrisca algumas hipóteses explicativas. A primeira delas refere-se a que

[...] uma fração da classe trabalhadora, principalmente da periferia das grandes cidades, vem sofrendo uma diminuição da libido (não sei se esse é o termo mais correto) devido a problemas de saúde e desgaste físico. O que me leva a pensar nesta hipótese são as jornadas de trabalho nas cidades grandes, que podem cobrir até 10 ou 12 horas por dia, acrescidas do tempo

\footnotetext{
${ }^{8} \mathrm{~A}$ bem da verdade, a incapacidade de prever o rápido declínio da fecundidade não se restringiu aos demógrafos brasileiros. Toda a comunidade internacional foi tomada de surpresa diante da queda da fecundidade, principalmente de seu ritmo, em inúmeros países da América Latina e da Ásia. Este é um tema que merece uma reflexão e uma análise crítica por parte dos demógrafos e estudiosos da população.
} 
gasto em transportes coletivos, que pode chegar a 2 ou 3 horas diárias. Se a isto se agregam os problemas de saúde e desnutrição que podem afetar diretamente a libido, tem-se todo o quadro completado. (Berquó, 1983)

As outras hipóteses de Berquó referemse ao cálculo econômico incorporado "mesmo a contragosto, para alguns", por uma fração da classe trabalhadora na decisão sobre o número de filhos e à inserção da mulher no mercado de trabalho.

Há de se louvar a atitude de Elza Berquó, ao autorizar a publicação do artigo três anos após sua apresentação no Seminário de Teresópolis. Como introdução, ao artigo original ela acrescenta duas páginas, sob o título de "Advertência (ou uma confissão)", onde faz reflexões e refere-se, em breve relato, aos avanços interpretativos alcançados após o seminário do Clacso. Afirma, nesta introdução, que sua primeira reação foi de não autorizar a publicação do artigo, pois ela própria "já havia avançado no sentido de algumas das hipóteses ali apenas esboçadas". Entretanto, "fora convencida do contrário - o pôr juntos os trabalhos [...] é importante como forma de eternizar aquele momento de reflexão [...] [pelo qual o Grupo do Clacso] passou ao longo de sua trajetória".

Um outro tipo de análise sobre o declínio da fecundidade foi apresentado por Carvalho, Sawyer e Paiva (1981). Os autores consideram a generalização do uso de anticoncepcionais, inclusive entre a população rural, porém não tomam esse fato como determinante, em um país onde não havia uma política oficial de planejamento familiar. Defendem a tese de que "o aspecto mais importante da queda da fecundidade seria a alteração do comportamento das populações de baixa renda" (idem, p. 56).

Nessa camada da população teriam ocorrido dois fenômenos fundamentais para a queda da fecundidade. O primeiro deles foi

[...] a intensificação do processo de proletarização que reduziu, drasticamente, a contribuição da produção doméstica para o consumo de uma grande parte da po- pulação brasileira. Isto tornou ainda mais difícil a criação de grandes famílias, em razão de ter cessado, em sua maior parte, a participação dos filhos na produção dos vários itens consumidos pela família. (idem, p. 57)

O segundo argumento tem a ver com a realidade específica do período:

na década de 1970, a despeito do pequeno aumento dos salários reais, os preços dos gêneros alimentícios aumentaram mais rapidamente do que os preços dos bens industrializados, o que reduziu ainda mais o padrão de vida da população de baixa renda e tornou menos factível a manutenção de famílias grandes. (ibidem)

Em 1983, em trabalho publicado pelo Committee on Population and Demography, da National Academy of Sciences, Merrick e Berquó (1983) apresentam estudo - o mais detalhado, até então, relacionado ao Brasil - sobre os determinantes do rápido declínio da fecundidade no país. Contando, também, com informações da Pesquisa Nacional de Reprodução Humana, que, coordenada pelo Cebrap, levantara dados em nove localidades de diferentes regiões do Brasil, os autores avançam as seguintes hipóteses:

a) o principal componente da queda teria sido o declínio da fecundidade marital;

b) o determinante próximo mais importante daquele declínio seria o aumento do controle dentro do casamento;

c) o declínio da fecundidade marital teria acontecido devido à generalização do controle da fecundidade dentro das regiões e grupos sociais mais pobres;

d) esses grupos teriam passado por transformações socioeconômicas, tais como o aumento da escolaridade, da posse de bens de consumo duráveis e da participação das mulheres no mercado de trabalho, que teriam engendrado normas favoráveis às famílias pequenas (Merrick e Berquó, 1983, p. 3-4). 
Uma análise do declínio da fecundidade no Brasil que sintetiza, em parte, as contribuições anteriores e amplia o seu escopo analítico é a de Faria (1989). Esse texto dá ênfase às mudanças institucionais, associadas "tanto ao processo de desenvolvimento excludente - e, portanto, ao processo de proletarização e empobrecimento - quanto ao padrão de intervenção do Estado capitalista brasileiro pós-1964". Não desconsidera, também, os determinantes próximos da fecundidade e pretende

[...] contribuir para o debate sobre a transição da fecundidade, introduzindo:

a) fatores de caráter cultural, sem cair no vazio das generalizações funcionalistas da teoria da modernização;

b) conseqüências não-antecipadas da ação governamental, sem uma visão conspiratória ou mecânica dessa ação;

c) uma modalidade de análise que enfatiza a complementaridade causal entre os processos estruturais e a ação dos atores, ultrapassando o falso dualismo entre determinação estrutural e ação individual. (Faria, 1989, p. 69)

A tese de Faria (1989) é a de que um conjunto de políticas governamentais gerou mudanças culturais de grande difusão espacial, provocando a institucionalização da demanda por uma regulação da fecundidade. As políticas governamentais mencionadas são as do crédito ao consumidor, de telecomunicações, de previdência social e de atenção à saúde. Os efeitos dessas políticas sobre a demanda pela regulação da fecundidade são considerados "conseqüências não-antecipadas". Entre as conseqüências, poder-se-ia listar:

a) fortalecimento do cálculo econômico como padrão de orientação na definição do número de filhos;

b) exposição da população à cultura médica;

c) separação, em termos de valores e normas, entre atividade sexual e atividade reprodutiva;

d) deslocamento da responsabilidade social (saúde, previdência) do eixo familiar para o Estado.
A institucionalização da demanda pela regulação da fecundidade, sem a oferta de meios relativamente eficientes de anticoncepção, com a necessária redução dos seus custos econômicos, sociais e psicológicos, e a não existência de uma

[...] política pública de oferta de meios de regulação da fecundidade, explícita e passível de controle democrático, permitiram que a demanda por esses meios tivesse de ser atendida, fundamentalmente, embora não exclusivamente, no mercado [...] todo esse processo acabou por adquirir um caráter profundamente discriminatório [...] desfavorecendo as camadas mais modestas da população. (Faria, 1989, p. 95)

$\mathrm{O}$ autor conclui que

a inexistência de uma política de oferta de meios de regulação da fecundidade, através de outros mecanismos que os de mercado, terminou por prejudicar os segmentos sociais mais modestos. E é justamente nisso que reside o efeito perverso dessa ausência. (Faria, 1989, 96; grifos do autor)

Digno de observação é que esse excelente texto de Faria não foi apresentado em reunião da Associação Brasileira de Estudos Populacionais (Abep) e, sim, em reunião da Associação Nacional de PósGraduação e Pesquisa em Ciências Sociais (Anpocs). Certamente, não seria fácil para os demógrafos e estudiosos da população responderem a uma questão colocada pelo autor, também associado da Abep:

[...] a oposição a uma política pública de oferta de meios de regulação, com o controle popular do seu desenho e de sua implementação, não teria tido resultados perversos, isto é, contrários àqueles que essa oposição desejava conseguir, na medida em que o resultado da ausência teria sido prejudicial aos grupos e setores sociais que se queria beneficiar e proteger? (Faria, 1989, p. 95)

O próprio autor adianta que, "em caso afirmativo, essa é uma das muitas peças que a dialética do processo social é capaz de pregar" (Faria, 1989, p. 96).

O biombo ideológico atrás do qual se alinhava a maioria dos demógrafos e estudiosos da população, na ampla contenda contra a interferência norteamericana e a sua visão de política da 
população, impediu que eles enxergassem as necessidades, e por elas lutassem, daqueles que seriam, pelo menos teoricamente, seus aliados. O resultado foi uma cumplicidade, mesmo que "não-antecipada", com efeito perverso sobre a população mais pobre, traduzida em um silêncio profundo sobre seu direito de regular a sua fecundidade.

As conseqüências deste maniqueísmo levaram a que a Assembléia da Abep, em 1980, votasse contra moção que pretendia que o IBGE se responsabilizasse por uma pesquisa nacional sobre fecundidade, no âmbito do World Fertility Survey (WFS), então implementado em vários países, tendo como base comum um questionário padrão. Sobre esse fato, reza a ata da Assembléia de 13 de outubro de 1980, ao relatar as deliberações tomadas: "[...] rejeitar por 28 (vinte e oito) votos contra 14 (quatorze) a favor e 18 (dezoito) abstenções, moção proposta pelo membro Maria Helena T. Henriques de que a Abep manifeste seu interesse e apoio a que a Fundação IBGE se faça responsável pela realização de uma pesquisa nacional de fecundidade" (Abep, 1980).

Um dos autores deste artigo era, então, presidente da Abep e votou pela rejeição da moção. Ainda bem que, em 1986, o suplemento da PNAD foi dedicado à fecundidade das mulheres brasileiras. Contou, então, com o apoio da Abep, inclusive na formulação do questionário.

Em 1990, a área de demografia do Cedeplar não aceitou, por decisão da maioria de seus membros, convite para participar da pesquisa DHS (Demographic and Health Survey) no Nordeste. O DHS, à semelhança do WFS, era um programa internacional de estudos comparativos, também baseado em um questionário padrão, mas que permitia adaptações segundo a realidade e interesses dos países envolvidos. Em 1996, foi aplicado no Brasil como um todo. Neste caso, com a participação, na discussão dos questionários, de alguns pesquisadores dos principais núcleos de demografia do país. Houve, então, da parte do Cedeplar, apoio logístico para a implementação da pesquisa em Minas Gerais, Espírito Santo e no Centro-Oeste.

Do lado dos grupos neomalthusianos, a primeira reação ao inesperado declínio da fecundidade foi creditá-lo ao aumento do número de abortos, ainda que, com isso, houvesse o reconhecimento implícito por forte demanda por anticoncepção (antes negada, daí a necessidade de intervenção). A ênfase no aumento da prevalência de aborto fortalecia o pleito pela implementação de serviços de planejamento familiar em todo o país, no qual estavam diretamente interessados. Até então, falava-se, sem nenhuma base empírica, em cerca de um milhão de abortos no Brasil por ano. Esta estimativa sofreu, de repente, alucinante aumento. O relatório do Banco Mundial de 1984 afirma que "calcula-se que entre 3 e 5 milhões de abortos ilegais e clandestinos são realizados anualmente no Brasil, ou aproximadamente um para cada nascimento" (World Bank, 1984).

Não tendo condições de desconhecer o rápido declínio da fecundidade no Brasil, na ausência de qualquer política governamental com esse objetivo, em vez de analisar a ocorrência do fenômeno, o relatório prefere comparar o caso brasileiro com os da Colômbia e do México, onde as políticas populacionais teriam sido responsáveis por uma queda nos níveis de fecundidade mais acentuada que a do Brasil. Não há referência às fontes utilizadas pelo relatório, entretanto as estimativas de pesquisadores brasileiros não confirmam as suas inferências. Pelo contrário, o declínio da fecundidade no Brasil, entre os finais das décadas de 60 e 70, foi superior ao do México e da Colômbia (World Bank, 1984).

Independente da posição dos demógrafos e estudiosos da população, a partir da segunda metade da década de 70 a anticoncepção espalha-se rapidamente pelo Brasil, com freqüência patrocinada por instituições privadas, como a Sociedade Civil de Bem-Estar da Família (Bemfam), aliadas a instituições médicas e amparadas numa deliberada omissão do Estado. Desde 1971, o governo federal havia reconhecido a Bemfam como entidade de utilidade pública (Fonseca Sobrinho, 1993). 


\section{Alguns programas governamentais na área do planejamento familiar e da saúde reprodutiva - o importante papel dos movimentos feministas}

Na Conferência Internacional de População de Bucareste, organizada pelas Nações Unidas em 1974, o governo brasileiro ainda se mantinha, oficialmente, favorável à tese de que, "em termos absolutos, não há problema de superpopulação no Brasil". Porém, e de acordo com a oposição antiimperialista dos seus próprios opositores, afirmaria:

A política demográfica brasileira é do domínio soberano do governo do Brasil. O governo não aceitará interferência de caráter oficial ou privado na sua política demográfica [...] O controle demográfico é uma decisão do núcleo familiar, o qual, a esse respeito, não deve sofrer interferência governamental. A capacidade de recurso ao controle da natalidade não deve ser um privilégio das famílias abastadas e, por isso, cabe ao Estado proporcionar as informações e os meios que possam ser solicitados por famílias de recursos reduzidos. (citado por Fonseca Sobrinho, 1993, p. 148)

Em 1978, o então presidente do Brasil, Ernesto Geisel, em entrevista concedida durante sua viagem ao México, foi explícito:

Nós achamos que a limitação da natalidade não deve ser imposta. Ela deve ficar ao arbítrio, ao desejo do casal. É o marido e a mulher que têm que resolver seu problema. Mas, eles devem ser informados sobre essa questão. E devem ter uma orientação de como realizar o seu planejamento familiar. Esse é o meu ponto de vista pessoal. Quero dizer que no Brasil isto ainda não está sendo praticado. (citado por Fonseca Sobrinho, 1993, p. 154)

$\mathrm{Na}$ sua mensagem ao Congresso Nacional, em 1983, em plena crise econômica, o presidente João Figueiredo convocou o Congresso para um amplo debate sobre a questão populacional, para que se determinassem as políticas adequadas a respeito. Justificava a mensagem, como se vê, com forte conotação neomalthusiana:
A explosão demográfica ocorre, sobretudo, nos países menos desenvolvidos, onde se comprimem cerca de dois terços da população mundial. No Brasil, nos últimos quarenta anos, o aumento demográfico ultrapassou 50 milhões de habitantes. Este crescimento humano, em termos explosivos, devora, como se tem observado, o crescimento econômico, agente da estabilidade; acarreta desequilíbrios sociais, econômicos, culturais e políticos que reclamam profunda meditação. (citado por Fonseca Sobrinho, 1993 , p. 136) ${ }^{9}$

A mensagem repercutiu no Congresso, que instalou uma Comissão Parlamentar de Inquérito cujo relatório final, aprovado em 1984, teve uma forte influência da Bemfam. O relator era membro do Grupo de Parlamentares para o Estudo de População e Desenvolvimento, ao qual a Bemfam, desde 1981, prestava assessoria. Foram quatro as conclusões do relatório:

1) a necessidade de formação de uma atitude consciente coletiva: a da "paternidade responsável";

2) a identificação do "planejamento da prole" como sendo um direito humano, onde a decisão cabe ao casal, devidamente informado;

3) a responsabilidade do Estado em fornecer as informações e os meios para que os casais possam implementar suas decisões;

4) a constatação de que tal responsabilidade ultrapassa os limites do Ministério da Saúde, devendo ficar a cargo de um Conselho Nacional de População e Planejamento Familiar, ligado diretamente à Presidência da República. (citado por Fonseca Sobrinho, 1993, p. 156)

Enquanto os parlamentares procuravam dar uma roupagem nova ao controle de natalidade, o Ministério da Saúde foi mais ágil. Contando com um grupo de médicos de longa tradição progressista e com a colaboração do emergente movimento das mulheres, deu início ao Programa de Assistência Integral à Saúde da Mulher (Paism). Já em 1983, o projeto começava a ser discutido no Congresso de Saúde Pública em São Paulo. A implantação do Paism foi conseqüência de uma compreensão do planejamento familiar como um dos

${ }^{9}$ Outras análises sobre o debate nas organizações do Estado, no parlamento e na sociedade civil podem ser encontradas em Rocha (1993) e Caetano (2004). 
componentes da saúde da mulher, fortalecida, principalmente, com a nova moldura política e ideológica introduzida pelo movimento feminista.

O movimento das mulheres cresceu e consolidou-se no Brasil assentado em dois pilares principais. Em primeiro lugar, o movimento internacional pelos direitos das mulheres, que envolvia uma nova visão do seu papel e da sua inserção social. Em particular, sobre os seus direitos reprodutivos e sobre a sua soberania em relação ao seu corpo e à sua sexualidade. A importância do movimento das mulheres fez a Organização das Nações Unidas proclamar 1975 como o Ano Internacional das Mulheres. Um outro pilar foi o processo de luta pela democratização do país, no qual o Movimento Feminino pela Anistia cumpriu um papel fundamental.

A presença das mulheres no cenário político do país foi fundamental para a emergência de uma nova visão do planejamento familiar. Entretanto, ligadas a diferentes grupos político-ideológicos, elas

[...] estiveram sempre oscilando entre orientações partidárias e autonomia para as suas reivindicações. Neste contexto, o planejamento familiar sempre foi área conflitiva. Era difícil para as mulheres aceitar sem discussão o laissez-faire em matéria de controle da reprodução, como pregava a esquerda. Por outro lado, não podiam se confundir com o antinatalismo proposto pela direita [...] Mas não pode haver prática feminista sem tocar nos temas da sexualidade, controle do corpo, respeito pelos desejos das mulheres, direito de aborto etc. [...] e como sufocar a discussão, uma vez que ela aponta para a necessidade de garantir às mulheres das classes populares o acesso aos instrumentos da contraconcepção? (Cardoso, 1983, p. 3)

Estava posto um novo paradigma político para se compreender o planejamento familiar. Não se tratava mais de discutir a relevância de se controlar a fecundidade para que o crescimento da economia fosse maior e mais justo. A própria história recente brasileira desmentia a tese controlista: a economia tinha crescido aceleradamente desde os anos 50, a fecundidade havia diminuído aceleradamente a partir da segunda metade dos anos 60 , e a pobreza continuava num patamar inaceitável. Não se podia mais considerar o planejamento familiar como uma panacéia para se reduzir a pobreza.

Mais ainda, a década de 80 marcou a transição do país para um regime político democrático, e apesar dos diversos obstáculos o seu êxito foi indiscutível. O autoritarismo na política passava para a história, era o desejo da sociedade: "nunca mais!". Com o processo de redemocratização, o autoritarismo implícito em muitas propostas controlistas foi para a lata de lixo da história. A sociedade democrática constrói-se baseada na garantia dos direitos políticos e sociais dos cidadãos. O movimento das mulheres sublinhou os seus direitos, inclusive os direitos reprodutivos. Estava posto um novo paradigma para o planejamento familiar. Mas, para caminhar decisivamente nessa direção,

seria necessário reconhecer a necessidade de uma política de saúde que garanta a todas as mulheres a informação e a assistência de que necessitem para exercer o direito de optar por ter ou não ter filhos, usando os métodos que escolham, sem qualquer constrangimento. (Cardoso, 1983, p. 5)

A preparação havida no Brasil para a Conferência Internacional de População e Desenvolvimento do Cairo (CIPD), de 1994, a própria constituição da delegação oficial do país (com representantes da Abep e de ONGs) e a sua atuação naquele evento atestam as mudanças profundas ocorridas tanto no seio da sociedade, quanto no nível governamental.

Após exaustiva interlocução com a sociedade civil organizada, aí incluídos os estudiosos de população e demógrafos, poder-se-ia dizer que a posição oficial levada pelo país à CIPD representava quase um consenso (Berquó, 1998). A divergência mais marcante partiu da Igreja Católica, sem no entanto atingir a radicalização e virulência constatadas em outros países latinoamericanos.

Pode-se afirmar que os pontos mais marcantes das resoluções da CPID, consubstanciados nas recomendações do Programa de Ação do Cairo-94, já constavam da proposta brasileira. Entre eles, 
dados os objetivos deste artigo, há que se ressaltar:

a) ao invés de se atribuir aos Estados o papel de definir o ritmo em que suas populações deveriam crescer, "conforme suas conveniências, a abordagem do Cairo se baseia, acima de tudo, nos diretos humanos e no conceito de desenvolvimento sustentável" (Alves, 1995);

b) "ênfase nos direitos sexuais e reprodutivos, ao invés do foco no planejamento familiar" (Alves, 2004, p. 37);

c) "incentivo às parcerias entre governos e ONGs na área da regulação da fecundidade e dos serviços de saúde reprodutiva" (Corrêa e Sen, citado por Alves, 2004).

Na verdade, o consenso levado à CIPD fora construído durante os anos 80 . Vale a pena fazer referência a uma assertiva da dra. Leila Linhares:

\begin{abstract}
A Constituição Brasileira de 1988 pode ser considerada como tendo se antecipado ao Plano de Ação de Cairo, ao reconhecer, por pressão principalmente do movimento das mulheres, o planejamento familiar como direito fundado nos princípios da dignidade humana $[. .$.$] sendo sua demanda de livre$ decisão do casal, competindo ao Estado propiciar o acesso necessário aos serviços e à informação e orientação para o exercício desse direito, vedando qualquer forma de coerção. (Tanaka et al., 2002, p. 41)
\end{abstract}

Atualmente, existem nos diferentes níveis de governo vários programas focados na atenção à saúde reprodutiva, incluindo a informação e distribuição de meios necessários à regulação da fecundidade. Estes programas ocorrem em um contexto de aceleradas mudanças sociais, econômicas e culturais, no Brasil e no mundo, em conjunto com o aperfeiçoamento da medicina ligada à saúde reprodutiva, grandes responsáveis pelo rapidíssimo declínio das taxas de fecundidade. Em 1970, a TFT das mulheres brasileiras era de, aproximadamente, 5,8 filhos nascidos vivos por mulher. Em 2000, em torno de 2,3!

O declínio da fecundidade no Brasil foi vertiginoso: a taxa de fecundidade total de
5,8 filhos nascidos vivos por mulher, em 1970, caiu para 2,3 em 2000. Contudo, nem todas as mulheres têm tido um acesso democrático aos meios contraceptivos e a todo o progresso técnico ligado à saúde reprodutiva. As dificuldades impostas pela seletividade do mercado e as deficiências dos serviços de saúde pública para a grande maioria da população feminina pobre ainda mantêm muitas mulheres como reféns da desinformação e da falta de acesso aos meios anticoncepcionais. Isto impede que vivam plenamente os seus direitos, já limitados pela própria pobreza: de fato, vivem uma cidadania limitada.

\section{Conclusão}

Ressuscitar o velho debate controlistas versus não-controlistas no início do século XXI seria repetir, como farsa, o que antes terminou em tragédia. Questões ideológicas postas há décadas foram superadas pela história. Hoje, os direitos sociais impõemse sobre as teorias que justificavam as velhas contendas. Para tornar ampla e irrestrita a cidadania das mulheres mais pobres, como a de todas as outras, cabe aos demógrafos e estudiosos da população não somente o reconhecimento, "em alto e bom som, da legitimidade do planejamento familiar" (Cardoso, 1983, p. 8), mas, também, que propugnem, como profissionais da área, que a ele tenham acesso as camadas mais pobres da população. Não se trata de uma interferência impositiva ou constrangedora, como ocorreu e ocorre em outros países, mas de criar condições, através do poder público, para que todas as mulheres possam cuidar de sua saúde sexual e reprodutiva e regular a sua fecundidade, segundo seus desejos e necessidades, podendo, assim, caminhar para o exercício de sua cidadania plena.

Não há mais motivos para buscar no passado o pano de fundo ideológico e, muito menos, para jogar para debaixo do tapete das velhas teorias as evidências de que a população não é uma variável neutra no processo social. Sabe-se, perfeitamente, que as variáveis demográficas não são exclusivamente dependentes ou determinadas por 
processos macroeconômicos, mas também determinantes. Aliás, deve-se a essa crença na neutralidade, alimentadora de batalhas gloriosas, porém equivocadas, no passado, o fato de que ainda se observa na demografia brasileira uma enorme dificuldade para reconhecer que o declínio da fecundidade, com as conseqüentes diminuição do ritmo do crescimento populacional e profunda mudança na estrutura etária, abriu para a sociedade novas oportunidades, assim como coloca sérios desafios. Se muito doloroso for, porque equivaleria a uma reavaliação crítica, ainda que sempre salutar, que não se usem expressões tais como "janela de oportunidades" ou "bônus demográfico". Porém, os profissionais da área têm a obrigação de, constantemente, chamar a atenção para essas oportunidades e desafios. As primeiras, em sua maioria, rapidamente se extinguirão e têm de ser aproveitadas enquanto duram. Os últimos têm de ser enfrentados, pois vieram para ficar. As tendências demográficas, hoje evidentes, são irreversíveis.

Nas regiões estagnadas, como o semiárido nordestino, onde a pobreza tornouse secular, ou em outras, como as grandes áreas metropolitanas, onde reside, atualmente, a maior parte da população mais pobre brasileira, a significativa proporção de filhos não desejados tornou-se parceira da miséria e da degradação social. Mulheres, reféns da sua cidadania incompleta, não

\section{Referências bibliográficas}

ABEP - Associação Brasileira de Estudos Populacionais. Ata da Assembléia Geral Ordinária realizada em 13 de outubro de 1980. Livro de Atas, n. 001, fls. 14-16 (manuscrito).

ALFONSO FRAGA, J.C. Cuba: una transición demográfica temprana y completa, la evolución de su populación en el siglo XX, antecedentes y perspectivas. Trabalho apresentado no Seminário Internacional de Población y Sociedad (Seposal), Salta, Argentina, junho de 2005.

ALVES, J.A.L. A Conferência do Cairo sobre População e Desenvolvimento e o para- têm tido a oportunidade de exercer seus direitos reprodutivos, inclusive o direito de regular sua fecundidade, segundo os seus desejos e necessidades. São socialmente empurradas, pela desinformação e falta de acesso aos meios de regulação, para a geração de uma prole que só tem tornado mais grave a sua situação social. A pobreza, repetindo o óbvio, não é fruto do crescimento populacional, mas a ele se articula em muitas circunstâncias, num círculo vicioso que precisa ser rompido por meio de diversas políticas sociais, entre elas $o$ planejamento familiar. Pode-se repetir, com Ruth Cardoso, mais de 20 anos depois: "Estas são as razões pelas quais uma política de planejamento familiar é uma política social inadiável no Brasil" (Cardoso, 1983, p. 7).

A demografia brasileira, nas últimas quatro décadas, cresceu e consolidou-se, seja através da Abep, seja através dos bons centros de pesquisa e ensino, seja através dos inúmeros profissionais espalhados pelos órgãos públicos e instituições de todo o país. Na América Latina, constitui uma das comunidades demográficas mais sólidas, com jovens gerações muito bem formadas, que nada devem às suas co-irmãs de outras partes do mundo. Muito se fez, mas ainda há muito por fazer. Que esta avaliação crítica sobre os nossos equívocos e silêncios no passado contribua para que não os reproduzamos no presente e no futuro.

digma de Huntington. Revista Brasileira de Estudos de População, vol. 12, ns. 1/2, jan.dez., p. 3-20, 1995.

ALVES, J.E.D. As políticas populacionais e os direitos reprodutivos: "o choque de civilizações" versus progressos civilizatórios. In: CAETANO, A.J., ALVES, J.E.D. e CORRÊA, $S$. (Orgs.), Dez anos do Cairo: tendências da fecundidade e direitos reprodutivos no Brasil. Campinas: Abep e UNFPA, 2004, p. 21-47.

BERQUÓ, E.S. Algumas indagações sobre a recente queda da fecundidade no Brasil. In: CLACSO (Org.), Familia reproduccion de 
la población y dinámica de la sociedad capitalista. São Paulo: Clacso, 1983, p. 207-228.

. O Brasil e as recomendações do Plano de Ação do Cairo. In: BILAC, E.D. e ROCHA, M.I.B. (Orgs.), Saúde reprodutiva na América Latina e no Caribe: temas e problemas. Campinas e São Paulo: Prolap, Abep, Nepo/Unicamp e Editora 34, 1998, p. 23-35.

BRITO, F. Crescimento demográfico e migrações na transição para o trabalho assalariado no Brasil. Revista Brasileira de Estudos de População, vol. 21, n. 1, jan.jun., p. 5-20, 2004.

CAETANO, A.J. O declínio da fecundidade e suas implicações: uma introdução. In: CAETANO, A.J., ALVES, J.E.D. e CORRÊA, S. (Orgs.), Dez anos do Cairo: tendências da fecundidade e direitos reprodutivos no Brasil. Campinas: Abep e UNFPA, 2004, p. 11-19.

CARDOSO, R. Planejamento familiar: novos tempos. Novos Estudos Cebrap, n. 3, nov., p. 2-7, 1983.

CARR, E.H. El socialismo en un solo país (1924-1926) Córdoba: Alianza, 1972.

CARVALHO, J.A.M. Analysis of regional trends in fertility, mortality and migration in Brazil, 1940-1970. Tese de doutorado. University of London, Faculty of Economics, 1973.

Evolução demográfica do Nordeste brasileiro comparada com a evolução demográfica do Brasil, 1940/1970. In: HADDAD, P.R. (Ed.), Desequilíbrios regionais e descentralização industrial. Rio de Janeiro: Ipea e Inpes, 1975, p. 11-35.

Evolução demográfica recente no Brasil. Pesquisa e Planejamento Econômico, vol. 10, n. 2, ago., p. 527-553, 1980.

CARVALHO, J.A.M. e GARCIA, R.A. Estimativas decenais e qüinqüenais de saldos migratórios e taxas líquidas de migração do Brasil, por situação do domicílio, sexo e idade, segundo unidade da Federação e macrorregião, entre 1960 e 1990, e estimativas de emigrantes internacionais do período (1985/2002). Trabalho apresentado no XIII Encontro Nacional de Estudos Populacionais, Ouro Preto, MG, 2002. Disponível em: <http: // www.cedeplar.ufmg.br/pesquisas/ migracao/index.html>.

CARVALHO, J.A.M., SAWYER, D.R. e PAIVA, $P$. The recent sharp decline in fertility in Brazil: economic boom, social inequality and baby bust. Cidade do México: The Population Council, 1981. (Working Paper, 8)

COALE, A. Population growth and economic development: the case of Mexico. Foreign Affairs, vol. 56, n. 2, January, p. 415-429, 1978.

COALE, A. e HOOVER, E.M. Population growth and economic development in lowincome countries: a case study of India's prospects. Princeton: Princeton University Press, 1958.

CORRÊA, S. e SEN, G. Cairo + 5: no olho da tempestade. Rio de Janeiro: Observatório da Cidadania, 1999.

DEMENY, P. Bucharest, México City, and beyond. Population and Development Review, vol. 11, n. 1, March, p. 99-106, 1985.

FARIA, V. Políticas de governo e regulação da fecundidade: conseqüências não antecipadas e efeitos perversos. In: ANPOCS (Org.), Ciências sociais hoje. São Paulo: Vértice e Anpocs, 1989, p. 62-103.

FINKLE, J.L. e CRANE, B.B. Ideology and politics at México City: the United States and the International Conference on Population. Population and Development Review, vol. 11, n. 1, March, p. 1-28, 1985.

FONSECA SOBRINHO, D. Estado e população: uma história do planejamento familiar no Brasil. Rio de Janeiro: Rosa dos Tempos e FNUAP, 1993.

FURTADO, C. A operação Nordeste. Rio de Janeiro: Ministério da Educação e Cultura, Instituto Superior de Estudos Brasileiros, 1959. 
GERMANI, G. Sociologia de la modernization: estudios teoricos, metodologicos y aplicados a America Latina. Buenos Aires: Paidós, 1969, caps. 4,6 e 7.

GREENHALGH, S. Science, modernity, and the making of China's one-child policy. Population and Development Review, vol. 29, n. 2, June, p. 163-196, 2003.

LEWIS, W.A. El desarrollo económico con oferta ilimitada de trabajo. In: AGARWALA, A.N. e SINGH, S.P., La economia del subdesarrollo. Madri: Editorial Tecnos, 1963, p. 333-374.

MALTHUS, T.R. Ensayo sobre el principio de la población. México: Fundo de Cultura Económica, 1951.

MARTINE, G. Éxodo rural, concentração urbana e fronteira agrícola. In: MARTINE, G. e GARCIA, R.C., Os impactos sociais da modernização agrícola. São Paulo: Caetés, 1987, p. 59-79.

MARTINE, G. e FARIA, V. Contexto social da política e da pesquisa em população no Brasil. Revista Brasileira de Estudos de População, vol. 3, n. 1, jan./jun., p. 1-23 1986.

MARX, K. O capital: crítica à economia política. 3a ed. Rio de Janeiro: Civilização Brasileira, 1975, Livro I, v. 2, cap. 23: A lei geral da acumulação capitalista, p. 712-827.
MERRICK, T.W. e BERQUÓ, E.S. The determinants of Brazil's recent rapid decline in fertility. Washington: National Academy, 1983.

POPULATION REPORTS. População e planejamento da natalidade na República Popular da China. Série J (edição em português), n. 25, dez., p. J1-J43, 1982.

ROCHA, M.I.B. Política demográfica e parlamento: debates e decisões sobre o controle da natalidade. Campinas: Nepo/ Unicamp, 1993. (Textos Nepo 25)

SIMONSEN, M.H. Brasil, 2002. Rio de Janeiro: Apec e Bloch, 1972.

Brasil, 2001. 5a ed. Rio de Janeiro: $\overline{\text { Apec e }}$ Bloch, 1975.

TANAKA, O.Y., CARVALHO, J.A.M., LINHARES, L. e MELO, C. Desenvolvimento de capacidades: a contribuição do FNUAP no Brasil. Relatório final. São Paulo e Brasília: Annablume e FNUAP, 2002.

WINCKLER, E.A. Chinese reproductive policy at the turn of the millennium. Populaton and Development Review, vol. 28, n. 3, September 2002.

WORLD BANK. World development report. Nova York: World Bank/Oxford University, 1984. 320p. Resenhado por PAIVA, P. e CARVALHO, J.A.M., Revista Brasileira de Estudos de População, vol. 2, n. 1, jan./ jun., p. 165-179, 1985.

\section{ANEXO 1}

\begin{tabular}{|c|c|c|c|c|c|c|c|c|}
\hline \multicolumn{9}{|c|}{ Brasil - séries P/F de algumas regiões e do país como um todo - 1970} \\
\hline $\begin{array}{l}\text { Idade } \\
\text { das } \\
\text { Mães }^{(1)}\end{array}$ & Norte $^{(2)}$ & Nordeste Central $^{(3)}$ & $\begin{array}{l}\text { Minas } \\
\text { Gerais e } \\
\text { Espírito } \\
\text { Santo }\end{array}$ & $\begin{array}{l}\text { Rio de } \\
\text { Janeiro }\end{array}$ & $\begin{array}{c}\text { São } \\
\text { Paulo }\end{array}$ & Paraná & $\begin{array}{l}\text { Rio Gde. } \\
\text { do Sul e } \\
\text { Santa } \\
\text { Catarina }\end{array}$ & Brasil \\
\hline $15-19$ anos & 1,87 & 1,62 & 1,54 & 1,46 & 1,54 & 1,22 & 1,46 & 1,56 \\
\hline 20-24 anos & 1,53 & 1,38 & 1,37 & 1,29 & 1,28 & 1,24 & 1,28 & 1,34 \\
\hline 25-29 anos & 1,28 & 1,39 & 1,40 & 1,34 & 1,31 & 1,28 & 1,39 & 1,34 \\
\hline 30-39 anos & 1,25 & 1,31 & 1,38 & 1,41 & 1,31 & 1,27 & 1,39 & 1,30 \\
\hline 40-49 anos & 1,13 & 1,29 & 1,37 & 1,38 & 1,32 & 1,25 & 1,42 & 1,27 \\
\hline
\end{tabular}

Fonte: Carvalho (1973). Baseada em dados brutos de IBGE, Tabulações Avançadas do Censo Demográfico de 1970.

(1) A partir de 30 anos, as tabulações avançadas apresentaram grupos etários com amplitude de 10 anos. Os multiplicadores para os 5,5 primeiros anos dos dois grupos decenais foram gentilmente calculados e disponibilizados pelo professor William Brass.

(2) Acre, Amazonas, Pará, Rondônia, Roraima e Amapá.

(3) Ceará, Rio Grande do Norte, Paraíba, Pernambuco e Alagoas. 


\begin{abstract}
Brazilian demography and the fall in fertility in Brazil: Contributions, mistakes and silences.

Since the late 1960s the Brazilian population has gone through a very rapid decline in fertility. In just three decades the overall annual fertility fell from 5.8 to only 2.3. The present article analyzes the positions of the experts in the field of population studies regarding this phenomenon. To understand their positions and attitudes, the international context during the 1960s and 1970s must be taken into account, polarized as it was by the tension between the socialist and the capitalist blocks. The majority of Brazilian social scientists, opponents of neo-Malthusianism, were against any type of presence of the State in the field of human reproduction. They held two strong convictions: 1) there was no demand for contraception in Brazilian society and 2) the pace of the Brazilian population growth, as well as the size of the country's population, were "neutral," from the standpoint of the welfare of individuals. This ideological debate has since become outdated. The changes in fertility in Brazil are quite advanced. However, some women, especially the poorest, still receive no information about or access to the means needed to plan the number of children they wish to have. On the other hand, Brazilian society is also failing to take advantage of opportunities created by the fall in fertility, and is not preparing itself to face the new challenges resulting from this very fall. Many demographers and population researchers are still "silent" as to these aspects.
\end{abstract}

Key words: Transition of fertility. Birth control. Neo-Malthusianism. Family planning.

Recebido para publicação em 14/07/2005. Aceito para publicação em 07/11/2005. 